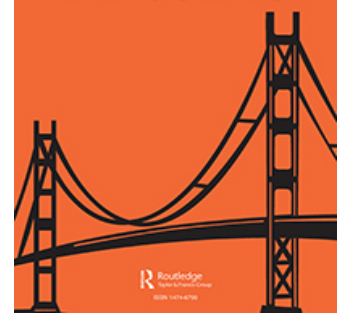

\title{
Universal Biology Does Not Prescribe Planetary Isolationism
}

\section{Carlos Mariscal}

To cite this article: Carlos Mariscal (2017) Universal Biology Does Not Prescribe Planetary Isolationism, Theology and Science, 15:2, 150-152, DOI: 10.1080/14746700.2017.1299384

To link to this article: https://doi.org/10.1080/14746700.2017.1299384

册 Published online: 26 Apr 2017.

Submit your article to this journal

Џ Article views: 47

Q View related articles $ک$

View Crossmark data \lceil 


\title{
Universal Biology Does Not Prescribe Planetary Isolationism
}

\author{
Carlos Mariscal
}

ABSTRACT

Stephen Hawking's caution against messaging extraterrestrial intelligence is a claim of universal biology and is probably false.

\section{KEYWORDS}

Universal biology; METI; SETI

Recently, physicist Stephen Hawking proposed a conclusion of universal biology: whenever one intelligent life world makes contact with another, the less developed life world is likely to be negatively affected by the interaction. As evidence, he references European encroachments into various parts of the world. It is true, of course, that this colonization was a net negative for Native Americans, Australian Aboriginals, and African tribes. Each of these groups suffered greatly, experiencing extermination, alienation, enslavement, or assimilation. By analogy, he likens messaging extraterrestrial intelligence (METI, also called Active SETI) to shouting in a jungle: you might get attention, but some of that attention is likely to be attention you would not want.

When discussing complex issues, it is reasonable to look to our best science. Biology, we realize, has deeply explored the nature of a single lineage, that from the Last Universal Common Ancestor (LUCA) to the diversity of life as we know it. We can make inferences about the nature of life elsewhere: such predictions may be justified by simple principles that underlie basic biological features, such as symmetry. Further justification for these inferences is limited as long as we have no other examples of what we might wish to call "life." This has been called the $N=1$ Problem. ${ }^{1}$ We know preciously little of what we expect to be the case, universally, for life. Nevertheless, we have very good reasons for supposing certain things: that parasites exist in all evolutionary systems, ${ }^{2}$ that certain levels of biological hierarchy are expected through general processes in evolution, ${ }^{3}$ and that interactions across very distinct ecosystems are likely to negatively impact one system at the expense of the other. ${ }^{4}$

So it seems Hawking might be justified based on certain inferences people make about life everywhere-when two populations intersect, there are three possible negative outcomes (bad for one, the other, or both), compared to a single a neutral outcome (neutral for both) and one positive outcome (good for both). In METI, we are actively seeking to interact with a completely distinct population, so caution would urge us toward a risk-averse outcome, lest we find ourselves in the same situation of native peoples facing European encroachment. Or, more accurately, native megafauna facing human expansion. 


\section{Fighting for fitness}

Like all arguments from analogy, his note of caution fails at some points of comparison. One reason populations intersecting leads to bad outcomes is because they can influence each other's fitness: an invasive rabbit may out-compete, out-reproduce, and overconsume, relative to native species. Across interstellar distances, these methods of competition are practically impossible. There is a reason I do not worry about Hawking denying me tenure-the academic and geographic distances are too vast.

So the analogy to human expansion fails due to interstellar distances if we assume alien civilizations will be unable to cross such distances in reasonable time spans. Perhaps the act of communication itself could cause harm on this planet, but likely no more than a YouTube comment section or pernicious hackers. But suppose as-yet-unknown alien technologies allow interstellar travel in short order. Such travel is not physically impossible under certain understandings of physics. Within the lifespan of the human species, perhaps, an alien civilization could receive our messages and cross millions of miles to reach Earth. Would Hawking's worries be justified then?

Probably not. On Earth, populations compete for resources because each perceives similar organic compounds as resources. An imported rabbit in Australia consumes a plant that may otherwise have fed a native wallaby. But now, compare a rabbit interacting with a methanogen archaeon. By sheer distance in how they acquire energy, there is little, if any, possible interaction between them where the success of one would affect the success of the other. They may overlap geographically, but their trophic needs are entirely unconnected. The same is likely to be true for any extraterrestrial creatures. Life, as we know it, is composed of a single chirality using six of the most common elements in the Universe: carbon, hydrogen, oxygen, nitrogen, phosphorus, and sulfur. It uses a nearly ubiquitous genetic code and interacts with millions of complex biomolecules. Nevertheless, the number of potential biomolecules vastly dwarfs those which we use on Earth. For biochemical reasons, a truly alien species on our planet is unlikely to view our organic molecules as energy, food, or even competition. So, even in the event an alien intelligence encountered our message and traveled vast interstellar distances to arrive here, it is unlikely that it would have any incentive to compete with Earth life for Earth-borne resources. I may not like rotifers, but their impact on my afternoon burrito is unlikely to be great or direct.

Furthermore, the distances are so vast and resource/competition possibilities so remote, it would have to be a particularly vindictive alien race to bear ill will towards Earthlings. During the 2016 U.S. presidential election, Canadian citizens uploaded videos describing positive features of Americans. We appreciated the effort and possibly sent a nice message back, but nobody traveled to Halifax to hug Canadian YouTubers. Nor did they travel to punch them. The effort to do either would have been entirely unreasonable, even though Canada is a neighboring country. Instead, we accepted the messages and, perhaps, sent some back.

So Hawking's argument fails in three distinct ways: (1) interstellar distances do not prescribe competition; (2) if such distances could be crossed it is unclear competition would result; and (3) it is uniformly irrational to exert a concerted effort to force a competition on a stranger simply because we became aware of them (if one could even do so). 


\section{Notes}

1. Carlos Mariscal, "Universal Biology: Assessing Universality from a Single Example," in The Impact of Discovering Life Beyond Earth, ed. Stephen Dick (Cambridge, UK: Cambridge University Press), 113-26.

2. See: M. Eigen, "Selforganization of matter and the evolution of biological macromolecules," Naturwissenschaften 58:10 (1971): 465-523; E.V. Koonin, T.G. Senkevich, and V.V. Dolja, "Compelling Reasons Why Viruses are Relevant for the Origin of Cells," Nature 29:7 (Jun 2009): 615; N. Takeuchi and P. Hogeweg, "Evolutionary Dynamics of RNA-like Replicator Systems: A Bioinformatic Approach to the Origin of Life," Physical Life Review 9 (2012): 219-63.

3. See: L. Fleming R. and Brandon, "Why Flying Dogs are Rare: A General Theory of Luck in Evolutionary Transitions," Studies in History and Philosophy of Science Part C: Studies in History and Philosophy of Biological and Biomedical Sciences 49 (2015): 24-31.

4. See; W.K. Dodds, Laws, Theories, and Patterns in Ecology (Berkeley: University of California Press, 2009); J.L. Lockwood, M.F. Hoopes, and M.P. Marchetti, Invasion Ecology (New York: John Wiley \& Sons, 2013).

\section{Disclosure statement}

No potential conflict of interest was reported by the author.

\section{Notes on contributor}

Carlos Mariscal is Assistant Professor of Philosophy at the University of Nevada, Reno, USA. 